\title{
SREBP transcriptional activity is mediated through an interaction with the CREB-binding protein
}

\author{
Jonathan D. Oliner, J. Michael Andresen, Stig K. Hansen, Sharleen Zhou, and Robert Tjian ${ }^{1}$ \\ Department of Molecular and Cell Biology, Howard Hughes Medical Institute, University of California, \\ Berkeley, California 94720-3204 USA
}

\begin{abstract}
The sterol regulatory element binding proteins (SREBP-1 and -2) activate transcription of genes whose products are involved in the cellular uptake and synthesis of cholesterol. Although considerable effort has been exerted to define the events regulating the levels of active SREBP, little is known about the transcriptional cofactors mediating SREBP function. In an unbiased search for potential coactivators of SREBP, we isolated a protein of $265 \mathrm{kD}$ from HeLa cells that directly bound SREBP-1 and SREBP-2. Peptide sequencing and Western blot analysis established that the $265-\mathrm{kD}$ protein was CBP (CREB-binding protein), a recently identified transcriptional coactivator. The putative activation domain of SREBP was shown to bind specifically to amino-terminal domains of recombinant CBP and p300 (a CBP-related protein). Moreover, transfection studies demonstrated that CBP enhances the ability of SREBP to activate transcription of reporter genes in HeLa cells. Together, these data suggest that CBP mediates SREBP transcriptional activity, thus revealing a new step in the biochemical pathway regulating cholesterol metabolism.
\end{abstract}

[Key Words: SREBP; CBP; transcriptional coactivators; cholesterol metabolism]

Received September 3, 1996; revised version accepted September 24, 1996.

Cholesterol is essential to humans and other animals both as a component of cellular membranes and as a biosynthetic precursor to molecules such as vitamin $D$ and steroid hormones (Goldstein and Brown 1977). Amounts of cellular cholesterol are strictly regulated in higher eukaryotes through a negative feedback mechanism (Brown and Goldstein 1986). Under circumstances of intracellular cholesterol depletion, the cell responds by stimulating transcription of genes whose products are involved in the uptake (LDL receptor gene) and synthesis (HMG-CoA synthase and HMG-CoA reductase genes) of cholesterol (Brown and Goldstein 1980; Goldstein and Brown 1984). Conversely, when cellular cholesterol levels are high, transcription of these genes is down-regulated. Cholesterol uptake occurs via binding of plasma low-density lipoprotein (LDL) to LDL receptors that reside on the surface of all cells. The LDL-bound receptor is internalized, and the cholesterol component of LDL is liberated for cellular use by the action of lysosomal enzymes (Goldstein et al. 1985).

Transcriptional regulation of the HMG-CoA synthase, HMG-CoA reductase, and LDL receptor genes is mediated through a DNA element common to the promoters of each of these genes /Goldstein and Brown 1990). Deletion of this sequence, known as the SRE (sterol regulatory element), specifically results in loss of

\footnotetext{
${ }^{1}$ Corresponding author.
}

feedback responsiveness to cellular sterol depletion. A synthetic SRE DNA fragment was used as an affinity probe to isolate two SRE-binding proteins, SREBP-1 and SREBP-2 (Hua et al. 1993; Wang et al. 1993; Yokoyama et al. 1993). The SREBPs, which share considerable amino acid sequence, have been shown in transfection experiments to act as transcription factors, increasing the expression of reporter genes containing SREs (Hua et al. 1993; Sato et al. 1994). Because the SREBP-1 and SREBP-2 proteins are extremely similar, for purposes of simplicity we will refer to them generically as SREBP when describing their shared characteristics.

Recent evidence indicates that SREBP itself is regulated by a proteolytic process whose activity is responsive to cellular sterol levels (Wang et al. 1994; Sakai et al. 1996). Nascent SREBP exists in a transcriptionally inactive form bound to the membranes of the endoplasmic reticulum and the nucleus. Under circumstances of sterol deprivation, SREBP is proteolytically cleaved, resulting in release of a soluble SREBP peptide into the cytoplasm. Following its subsequent migration into the nucleus, this peptide binds the SRE and up-regulates gene expression through either direct or indirect communication with as yet unidentified components of the transcription machinery.

In an initial search for proteins within the transcription apparatus that might serve such a coactivator role, we tested the RNA polymerase II (Pol II) TAFs (TBP- 
associated factors) (Dynlacht et al. 1991) for a potential interaction with SREBP-1. The Pol II TAFs, along with TBP (TATA box-binding protein), constitute the general transcription factor TFIID, which is an integral component of the transcription machinery. Several of these TAFs have been shown to act as transcriptional coactivators, binding directly to the activation domains of sequence-specific transcription factors such as Spl (Chen et al. 1994; Gill et al. 1994), VP16 (Goodrich et al. 1993; Klemm et al. 1995), p53 (Lu and Levine 1995; Thut et al. 1995), bicoid (Sauer et al. 1995), and hunchback (Sauer et al. 1995). Through these interactions with Pol II TAFs, it is thought that enhancer-binding factors can recruit the transcription apparatus to specific promoters to stimulate the production of messenger RNA (Goodrich and Tjian 1994; Sauer et al. 1995). In contrast to results obtained with many other activators, SREBP immobilized on beads failed to interact specifically with the Pol II TAFs (data not shown). This result suggested that SREBP might direct transcriptional activation by contacting other targets in the transcription apparatus, including factors that are not intrinsic components of the preinitiation complex.

To address these possibilities in a systematic manner, we used an SREBP protein probe in Far Western blot analysis to search for potential SREBP-interacting proteins that might be present in crude human and Drosophila cell nuclear extracts. Remarkably, this screen yielded a single protein of $265 \mathrm{kD}$ (p265) from both species that bound specifically to the activation domains of both SREBP-1 and SREBP-2. The p265 protein was purified on a preparative scale, and its identity was determined by peptide microsequencing. Subsequent binding studies performed with recombinant fragments of p265 confirmed the interaction and permitted mapping of the SREBP-binding domain on p265. Finally, cotransfection experiments in HeLa cells revealed that p265 acts to stimulate SREBP-dependent transcriptional activation. These results implicate p265 as a candidate coactivator for SREBP and define a new step in the cholesterol regulatory pathway.

\section{Results}

\section{Biochemical screen for SREBP-binding proteins}

It was shown previously that a 90 -amino-acid aminoterminal deletion of hamster SREBP-1 abolished the protein's ability to activate transcription in mammalian cell transfection experiments (Sato et al. 1994). Moreover, the truncation imparted dominant-negative activity, as cotransfection of this shorter SREBP-1 form along with nonamino-terminally truncated SREBP-1 inhibited the latter's transcriptional activity. These data suggested that the 90-amino-acid deletion crippled the activation domain of SREBP-1 without adversely affecting its ability to bind DNA (the DNA-binding domain of SREBP-1 is not contained within this deletion).

On the basis of these results, we designed a screen to isolate proteins that might contact the SREBP activation domain and thereby mediate its function. Recombinant proteins containing amino acids $1-323$ or $91-323$ of human SREBP-1 fused to the carboxyl terminus of glutathione $S$-transferase (GST) were produced in Escherichia coli (referred to as GS1 and GS1 $1 \Delta$, respectively). GST fusion proteins incorporating homologous regions of human SREBP-2 (amino acids 1-330 and 94-330) were also produced (called GS2 and GS2 2 , respectively). As an initial experiment, both SREBP-2 proteins were radioactively labeled and used individually to probe Far Western blots containing proteins derived from crude HeLa cell nuclear extracts. The GS2 probe recognized a single band migrating at $265 \mathrm{kD}$ (p265), whereas GS2 $\Delta$ failed to bind any of the proteins on the membrane (Fig. 1A).

To determine whether SREBP-2 could also associate with p265 in solution, glutathione-agarose beads prebound to the GST fusion proteins were incubated with crude HeLa nuclear extracts. Bound HeLa cell proteins were eluted with SDS sample buffer, separated by PAGE, transferred to nitrocellulose membranes, and probed with labeled GS2. The p265 band was apparent in the lane corresponding to the GS2 pulldown but not in the adjacent lane in which GS2 $\Delta$ was used as the affinity resin (Fig. 1B, lanes 3,4). Strikingly, GS1 and GS1 $\Delta$ behaved identically to their SREBP-2 counterparts in this assay, suggesting that the activation domains of both SREBP family members interact with the same $265-\mathrm{kD}$ protein (Fig. 1B, lanes 1,2). This notion is further supported by the finding that the SREBP-2 Far Western probe recognized the band precipitated by the SREBP-1 affinity beads.

Transfection of mammalian SREBP-1 and SREBP-2 expression vectors into both mammalian (Hua et al. 1993; Sato et al. 1994) and Drosophila (Sanchez et al. 1995) cells (Schneider cells) has been shown to result in transcriptional activation of SRE-containing reporter genes, indicating that the mechanisms used by flies and mammals to support SREBP-induced transcription are functionally conserved. Thus, if the role of p265 in binding both SREBPs is to serve as a transcriptional coactivator, one might expect that a functional equivalent to p265 would also exist in Drosophila. To test this possibility, we performed an identical assay to that shown in Figure 1B, except that Schneider cell nuclear extracts were substituted for HeLa cell nuclear extracts. Consistent with our prediction, the activation domains of both SREBPs interacted specifically with a protein present in the Drosophila extract (Fig. 1C, lanes 1,2,4). As this band migrates at virtually the same size as a human p265, it may represent a Drosophila p265 homolog.

\section{Purification of $p 265$}

In an effort to purify p265, we sought initially to determine whether the protein was sufficiently abundant to directly visualize in gels. Crude HeLa cell nuclear extracts were bound to each of the four GST-SREBP affinity resins, eluted with SDS sample buffer, separated by PAGE, and stained with silver. Remarkably, both GS1 and GS2 precipitated the same set of four high-molecu- 
A

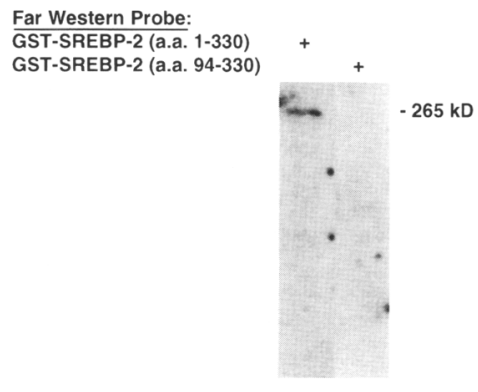

B

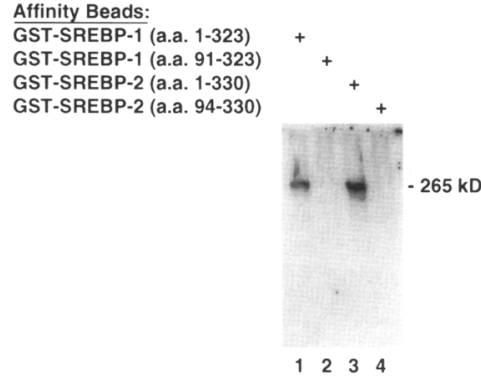

Far Western Probe: GST-SREBP-2 (a.a. 1-330)
C

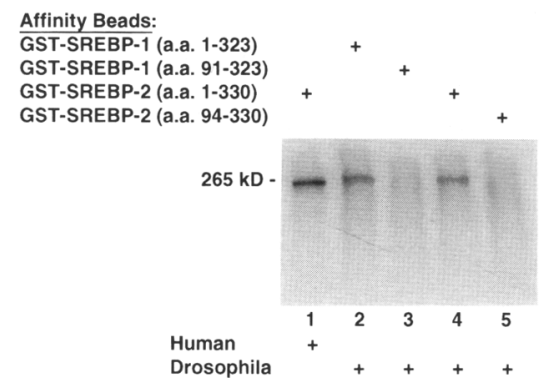

Far Western Probe: GST-SREBP-2 (a.a. 1-330)

D Affinity Beads:

GST-SREBP-1 (a.a. 1-323) +

GST-SREBP-1 (a.a. 91-323) +

GST-SREBP-2 (a.a. 1-330)

GST-SREBP-2 (a.a. 94-330)

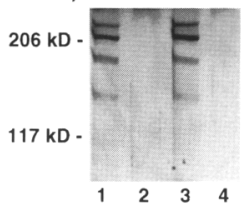

Silver Stain
Figure 1. Screen for proteins that interact with the SREBP activation domain. $(A-C){ }^{32}$ P-labeled GST fusion proteins were used as Far Western blotting probes to detect SREBP-interacting proteins in crude HeLa nuclear extracts $(A)$ and affinity bead precipitations from crude HeLa $(B)$ and Schneider $(C)$ nuclear extracts. The size of $\mathrm{p} 265$ was determined by extrapolation from a plot of marker values vs. gel migration distance (data not shown). (D) Proteins were precipitated as in $B$ and stained with silver. lar-weight bands after only this one purification step (Fig. 1D, lanes 1,3). Furthermore, the association appeared to be specific, as GS1 $\Delta$ and GS2 $\Delta$ failed to bind any proteins in the HeLa nuclear extract (Fig. 1D, lanes $2,4)$.

The highest molecular weight band detected by silver staining comigrated with the $265-\mathrm{kD}$ protein identified by Far Western blotting, prompting us to focus our attention on this band. To determine whether the $265-\mathrm{kD}$ signal observed in each of these assays represented the same protein, crude HeLa nuclear extracts were further fractionated and reassayed by both methods. Upon fractionation by phosphocellulose chromatography, the p265 Far Western signal was shown to peak at a salt elution step of $0.3 \mathrm{M} \mathrm{KCl}$ (Fig. 2A, lane 4). The $0.3 \mathrm{M} \mathrm{KCl}$ eluate was dialyzed to $0.1 \mathrm{M} \mathrm{KCl}$ and subsequently fractionated by anion exchange chromatography (Poros $Q$ resin). Both Far Western blotting and silver staining of the resultant fractions revealed superimposable patterns of gradient elution activity with respect to the $265-\mathrm{kD}$ signal (Fig. 2B, middle and upper panels). By both assays, the abundance of $\mathrm{p} 265$ peaked in fractions 5 and 6 /to avoid confusion, it should be noted that in this experiment p265 was not the lowest mobility band seen on silver staining; a band of $\sim 300 \mathrm{kD}$, which was not reactive by Far Western blotting and which we had not observed previously, eluted in fractions 6-11). Taken together, these results suggest strongly that both assays detected the same SREBP-binding activity.

As p265 appeared to be relatively abundant, we chose to purify it on a preparative scale to determine its identity by peptide sequence analysis. GS2 affinity resin was incubated with phosphocellulose-fractionated HeLa nuclear extracts, followed by high-salt elution of bound proteins. The eluted proteins were separated by SDSPAGE and transferred to a nitrocellulose membrane, and the p265 band was excised for microsequencing. Using the resultant peptide sequences (Fig. 2C) as templates to search protein data bases, p265 was unambiguously identified as the human CREB-binding protein (CBP), a recently isolated $265-\mathrm{kD}$ protein that exhibits properties of a transcriptional coactivator (Arias et al. 1994; Kwok et al. 1994; Bannister and Kouzarides 1995; Dai et al. 1996; Kamei et al. 1996).

To further ensure that CBP was the SREBP-binding protein, Western blots derived from the Poros Q-fractionated HeLa nuclear extracts described above were probed with antibodies directed against mouse CBP. This antiserum recognized a polypeptide of $265 \mathrm{kD}$ whose elution pattern exactly matched that observed by silver staining and Far Western blotting (Fig. 2B, lower panel), confirming the equivalence of p265 and CBP.

\section{Mapping CBP'S SREBP-interacting domain}

We then sought to map the SREBP-binding domain on CBP. Crude E. coli protein lysates containing recombinant mouse CBP fusion proteins (CBP amino acids 1-682, 451-682, or 1680-1891) were electrophoretically separated, blotted, and probed with GS2. As shown in Figure 3 , the probe bound avidly to amino-terminal fragments of CBP (amino acids 1-682) and p300 (amino acids 1-663) (Yee and Branton 1985; Harlow et al. 1986), a paralog of CBP. To a somewhat lesser extent, GS2 also 
A

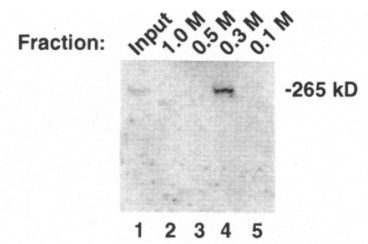

Far Western Probe: GST-SREBP-2 (a.a. 1-330)

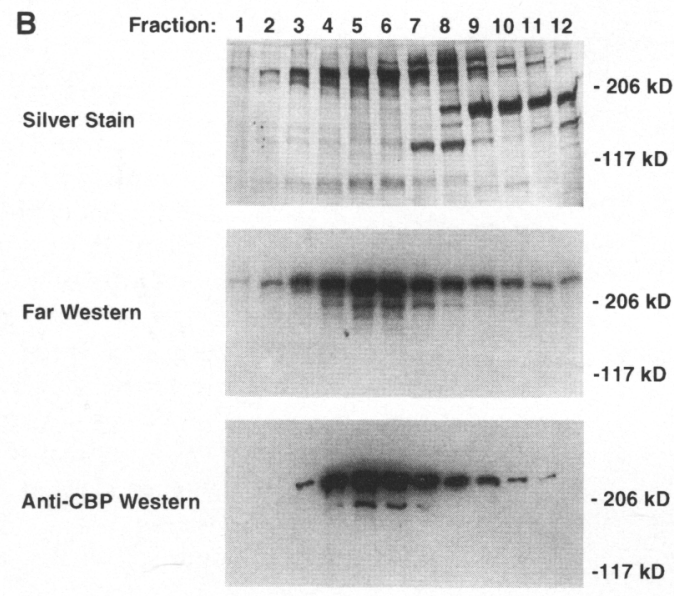

C Peptide B-6067 Human CBP Humą p 300 Peptide C-6161 Human CBP Human p 300

Peptide B-6059 Human $\mathrm{CBP}$ Human p300

Peptide B-6070 Human CBP Human $\mathrm{p} 300$

$$
\begin{aligned}
& \text { KGEPRSEMMEEDLQGASQV } \\
& \text { KGEPRSEMMEEDLQGASQV (a.a. 1014-1032) } \\
& \begin{array}{lll}
K E &
\end{array} \\
& \text { KRLQEWYK } \\
& \text { KRLQEWYK (a.a. 1497-1504) } \\
& \text { KRLQEWYK (a.a. 1461-1468) } \\
& \text { KLYATM } \\
& \text { KLYATM (a.a. 1620-1625) } \\
& \text { KLYATM (a.a. 1583-1588) } \\
& \text { KWGLGL } \\
& \text { KWGLGL (a.a. 1744-1749) } \\
& \text { K GLGL (a.a. 1707-1712) }
\end{aligned}
$$

Figure 2. Purification and identification of p265. (A) Far Western blot to detect p 265 in HeLa nuclear extracts fractionated by phosphocellulose chromatography. The eluate containing peak p265 activity (lane 4 ) was further fractionated $(B)$ by anion exchange chromatography (Poros Q) with column loading at $0.1 \mathrm{M}$ $\mathrm{KCl} \mathrm{HEMG}$ and elution by salt gradient from $0.1 \mathrm{M}$ to $1 \mathrm{M} \mathrm{KCl}$ HEMG. The 12 fractions shown represent eluates from the initial portion of the gradient $(0.1-0.37 \mathrm{M} \mathrm{KCl} \mathrm{HEMG)}$. Each of the resulting fractions was purified in batch with GST-SREBP-2 (amino acids 1-330) affinity beads and assayed by silver staining, Western blotting (polyclonal anti-CBP), and Far Western blotting [GST-SREBP-2 [amino acids 1-330)] using the probes indicated in parentheses. $(C)$ Alignment of p265 peptide sequences with human CBP and p300. Areas in which p300 fails to match the peptide sequences are shown in gray.

interacted with a smaller region of CBP (amino acids 451-682), containing the CREB-binding domain (Lundblad et al. 1995). By comparison, GS2 interacted about 50 -fold less efficiently with more carboxy-terminal portions of both CBP and p300 [the E1A-binding domains of both proteins (Arany et al. 1995; Lundblad et al. 1995)].

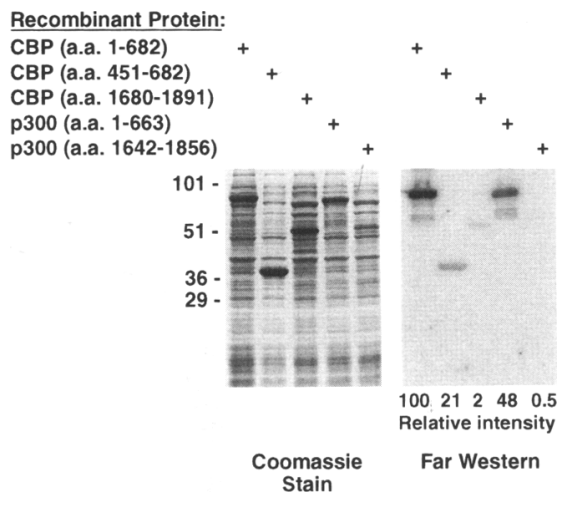

Figure 3. Interaction between the SREBP-2 activation domain and recombinant versions of CBP and $\mathrm{p} 300$. Crude $E$. coli lysates containing overexpressed CBP and $\mathrm{p} 300$ proteins were assayed either by Coomassie staining (left) or Far Western blotting [right; GST-SREBP-2 (amino acids 1-330) probe]. Proteins CBP (amino acids 1-682), CBP (amino acids 451-682), and p300 (amino acids $1-663$ ) were produced as fusions to GST. The remaining proteins were expressed as fusions to a six-histidine affinity tag. The relative intensities of Far Western blotting signals were determined by PhosphorImager (Fuji Bas 1500), and values represent the average of duplicate blots.

Moreover, the probe had no discernible affinity for any native $E$. coli proteins, providing further support for the specificity of the SREBP-CBP interaction. These results suggest that the activation domains of SREBP-2 and CREB may share a common or overlapping target binding region on CBP (Lundblad et al. 1995) (amino acids 451-682). The data also demonstrate that eukaryotic protein modifications are unnecessary for CBP-SREBP interaction, as all mammalian proteins used in these assays were produced in $E$. coli. In contrast, it has been shown previously that CREB must be phosphorylated to bind CBP (Chrivia et al. 1993).

\section{Functional characterization of the SREBP-CBP interaction}

To determine the functional implications of the SREBPCBP interaction, we performed transfection experiments in HeLa cells. Transfection of expression vectors encoding either hamster SREBP-1 (amino acids 1-410) or human SREBP-2 (amino acids 1-462) stimulated the activity of a reporter construct containing a single copy of the SRE in its native context within the LDL receptor promoter (Fig. 4A, bars 7,11 ) but failed to stimulate a reporter lacking the LDL receptor promoter sequences (Fig. 4A, bars 1-3). Furthermore, the addition of increasing amounts of CBP expression construct resulted in a progressive enhancement of activator-dependent reporter activity (Fig. 4A, bars 8,9,12-14). The CBP titrations had little effect on basal reporter activity (Fig. 4A, bars 4-6).

To rule out any indirect effects of CBP on SREBP that might be unrelated to the SREBP activation domain and to allow for the controlled comparison of several activators on a single promoter, we constructed mammalian 
A

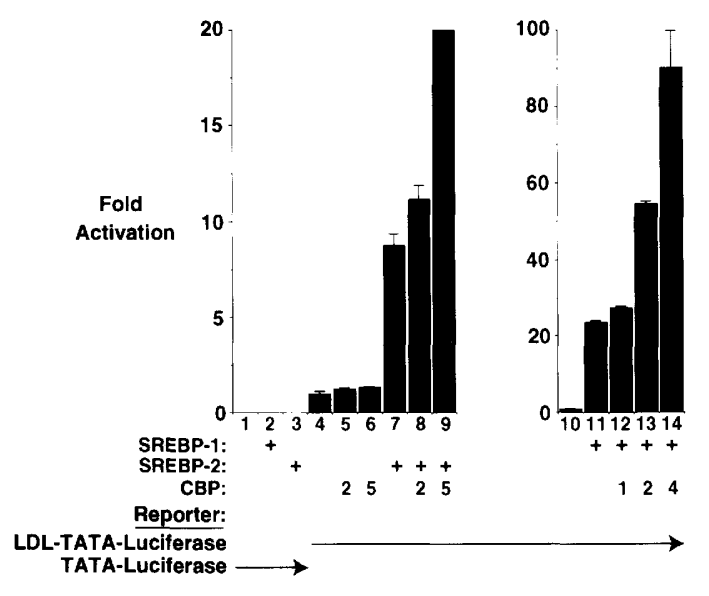

B

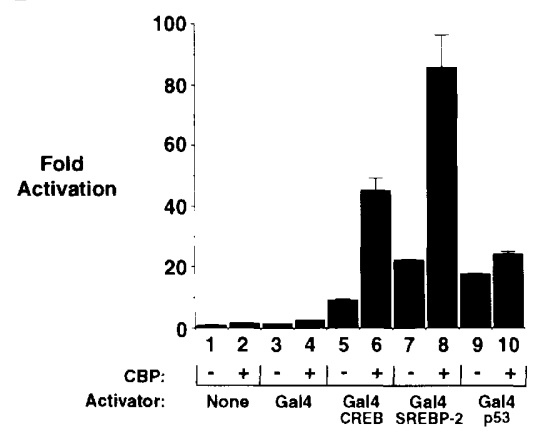

Figure 4. Functional characterization of the SREBP-CBP interaction by transfection. (A) HeLa cells were transfected with CMV promoter-driven expression constructs encoding hamster SREBP-1 (amino acids 1-410) or human SREBP-2 (amino acids 1-462) (250 ng and $400 \mathrm{ng}$ per well, respectively) in six-well plates by calcium phosphate precipitation. pCMV-CBP was cotransfected in the indicated amounts $(\mu \mathrm{g})$. Five hundred nanograms each of reporter plasmid (pLDL-Syn-TATA-luc or pSynTATA-luc; described in Materials and Methods) and transfection control vector (pCMV-lacZ) were used in each transfection. Where necessary, $\mathrm{CMV}$ vector lacking an insert was added to equalize the total amount of CMV expression plasmid present in each transfection. All luciferase values (mean \pm S.D.) have been corrected for variations in $\beta$-galactosidase activity (a measure of transfection efficiency|. Values represented by bars 1-9 and 10-14 have been normalized to basal reporter activity (bars 4 and 10, respectively). (B) Transfections were performed and analyzed as above. A plus sign indicates the inclusion of 5 $\mu \mathrm{g}$ of pCMV-CBP in the transfection. The reporter used in all transfections was pG2-TK-luc, a luciferase reporter containing two tandem Gal4 DNA-binding sites upstream of the herpes simplex virus thymidine kinase promoter. The activator constructs (described in Materials and Methods) were used in the following amounts (ng per transfection): pCMV-Gal4, $150 \mathrm{ng}$; pCMV-Gal4-SREBP-2 (amino acids 1-330), $50 \mathrm{ng}$; pCMVGal4-CREB (amino acids 1-283), 90 ng; pCMV-Gal4-p54 (amino acids 1-42 duplicated), $500 \mathrm{ng}$. Because the CREB activation domain must be phosphorylated to interact with CBP, a construct expressing the catalytic domain of protein kinase A (Maurer 1989) was included in the Gal4-CREB transfections (1 $\mu \mathrm{g})$. expression vectors encoding the yeast Gal4 DNA-binding domain fused to the activation domains of three different transcription factors: SREBP-2 (amino acids 1-330), CREB (amino acids 1-283), and p53 (amino acids 1-42 tandemly duplicated). Gal4-CREB served as a positive control in these experiments, having been shown previously to be responsive to the effects of CBP in transfections (Arany et al. 1995). In contrast, no physical or functional relationship has been demonstrated between p53 and CBP. p53 has been shown to activate transcription via interaction with the $\mathrm{TAF}_{\mathrm{II}} 40$ and $\mathrm{TAF}_{\mathrm{II}} 60$ coactivators (Lu and Levine 1995; Thut et al. 1995). When transfected into HeLa cells, all three of these Gal4 fusion constructs directed transcriptional activation of a reporter containing two Gal4 DNA-binding sites upstream of a herpes simplex virus thymidine kinase core promoter sequence (Fig. 4B, bars 5,7,9). In contrast, expression of the Gal4 DNA-binding domain alone had no effect on reporter activity (Fig. 4B, bar 3). Coexpression of CBP markedly enhanced the Gal4-CREB and Gal4SREBP-2 reporter stimulation (Fig. 4B, bars 6,8). CBP expression also had a slight effect on reporter activity in the presense of Gal4-p53, but this marginal relative induction was also observed in the presense of Gal4 only and in the absense of activators, suggesting that this reporter stimulation was p53 independent (Fig. 4B, bars $2,4,10$ ). Together, these transfection data provide functional support for the hypothesis that CBP plays a role in transducing the SREBP transcriptional activation signal.

\section{Discussion}

Searching in an unbiased manner for factors that might mediate the activating signal of SREBP, we isolated the recently identified transcriptional coactivator known as CBP. By Far Western blotting, as well as interaction assays in solution, human CBP derived from a cell extract was shown to bind specifically to the activation domains of both SREBP-1 and SREBP-2. This interaction was confirmed using recombinant versions of CBP, and the region on CBP that contacts SREBP was mapped to its amino-terminal domain. The amino terminus of $\mathrm{p} 300$, a protein whose functional properties are indistinguishable from those of CBP, was also shown to interact with SREBP. Furthermore, these experiments revealed that a Drosophila protein of similar size to human CBP specifically bound both SREBP activation domains. Finally, transfection studies demonstrated that $\mathrm{CBP}$ enhances the ability of SREBP to activate transcription of reporter genes in HeLa cells, thus suggesting that CBP may serve a coactivator role for SREBP similar to that shown for other transcriptional activators (Janknecht and Hunter 1996).

CBP was first isolated in a systematic screen for CREBinteracting proteins (Chrivia et al. 1993). Using candidate approaches, CBP and/or p300 has been shown to bind also to c-Jun (Arias et al. 1994), c-Fos (Bannister and Kouzarides 1995), YY1 (Lee et al. 1995), c-Myb (Dai et al. 1996; Oelgeschlager et al. 1996), MyoD (Yuan et al. 1996), and nuclear receptors (Kamei et al. 1996). The 
characteristics of each of these activator-coactivator interactions have unique features. For example, whereas SREBP, CREB, c-Jun, and c-Myb appear to bind a common region of CBP (amino acids 461-682), the nuclear receptors bind the extreme amino terminus (CBP amino acids 1-101), and c-Fos binds amino acids 1621-1877. Additionally, the activator-coactivator contacts differ in their requirements for protein modification. For example, CREB requires phosphorylation by the cAMP-dependent protein kinase (PKA) to interact with CBP and p300. This modification appears to be an intrinsic regulatory feature of this biochemical pathway. For several other transcription factor-CBP/p300 interactions, however, the binding does not appear to require eukaryotic protein modification. From a teleological standpoint, it is understandable that such modifications would be dispensible for those activators whose activity is modulated by other mechanisms. The function of SREBP, for example, is already tightly controlled by proteolytic cleavage, whereas the activities of the nuclear receptors are regulated by ligand binding.

CBP and p300 augment activation of all transcription factors that they have been shown to bind, suggesting that CBP and p300 may serve a general role in coactivating transcription by a large number of sequence-specific activators. The mechanism by which CBP and p300 transmit their signals to up-regulate transcription is therefore of considerable interest, and several studies have attempted to address this question. Kwok et al. (1994) showed that bringing CBP to a promoter is sufficient to activate transcription, even in the absense of an added enhancer factor. In this study a transfected construct expressing a carboxy-terminal portion of CBP (lacking the CREB- and SREBP-interaction domains) fused to the yeast Gal4 DNA-binding domain was observed to stimulate expression of a reporter gene bearing Gal4 DNA-binding sites [a similar result was subsequently obtained using Gal4-p300 fusions (Yuan et al. 1996)]. They further showed that this region of CBP was capable of contacting TFIIB, a general transcription factor for RNA Pol II transcription. It has been reported additionally that p300 binds either directly or indirectly to TBP (Abraham et al. 1993) and that CBP associates with RNA Pol II (Kee et al. 1996). These data suggest the possibility that $\mathrm{CBP}$ and p300 play a role in recruiting the basal transcription apparatus to p300/CBP-responsive promoters. Nonetheless, it is still too early to discern whether these interactions play such a role in vivo.

Recently, Yang et al. (1996) reported an interaction between $\mathrm{p} 300 / \mathrm{CBP}$ and a novel protein that they called $\mathrm{p} / \mathrm{CAF}$ ( $\mathrm{p} 300 / \mathrm{CBP}$-associated factor). The discovery of this interaction was intriguing for two reasons. First, $\mathrm{p} / \mathrm{CAF}$ was demonstrated to compete with the adenoviral E1A protein for binding to a carboxy-terminal region on p300 and CBP. ElA had been shown previously to down-regulate both $\mathrm{p} 300$ and CBP activity via its interaction with these coactivators $(\mathrm{p} 300$ was initially isolated as an E1A-interacting protein) (Yee and Branton 1985; Harlow et al. 1986; Arany et al. 1995; Lundblad et al. 1995). Interestingly, transfected $\mathrm{p} / \mathrm{CAF}$ and E1A have antagonistic effects on cell cycle progression, implying that $\mathrm{p} 300 / \mathrm{CBP}$ function may be regulated or mediated through the domain targeted by $\mathrm{p} / \mathrm{CAF}$ and ElA. The other remarkable finding of this study was that $p / C A F$ appeared to exhibit intrinsic histone acetylase activity. Although the function of histone acetylation has not been fully elucidated, it is thought to be involved in the restructuring of chromatin architecture (Turner 1993; Wolffe 1994|. Thus, p/CAF might transduce the p300/ CBP signal through displacement or repositioning of histones, which might, in turn, indirectly facilitate recruitment of the transcription apparatus to specifically targeted promoters. This is a tantalizing hypothesis in light of recent observations that the synergistic transcriptional activation mediated by SREBP and Spl observed in vivo (Briggs et al. 1993; Sanchez et al. 1995) can only be reiterated in vitro when histones are incorporated into DNA templates (K. Robinson, J. Kadonaga, J. Oliner, and $\mathrm{R}$. Tjian, unpubl.). It is interesting that the cooperative effects of another pair of sequence-specific transcription factors, c-Myb and NF-M, may also be mediated by CBP (Oelgeschlager et al. 1996), although the mechanism underlying synergism in this system is unknown.

Although this work reveals an additional step in the metabolic cascade regulating cellular cholesterol levels, the mechanism through which CBP transmits its signal from SREBP (and other transcription factors) to the transcription machinery remains to be defined in detail. It should be emphasized that the above mechanisms proposed to account for CBP function in transcription are not mutually exclusive nor do they preclude the involvement of other interactions in the transmission of the CBP signal. Other factors, including the nuclear hormone receptor coactivator SRC-1 (Onate et al. 1995; Kamei et al. 1996), are being evaluated in this regard (Janknecht and Hunter 1996). Given the growing number of activators whose effects are mediated through CBP, it is likely that elucidation of the pathway in which CBP acts will have wider implications for the study of transcriptional control.

\section{Materials and methods}

E. coli expression plasmids

BamHI-EcoRI-digested PCR products encoding human SREBP-1 (amino acids 1-323 and 91-323) and human SREBP-2 (amino acids 1-330 and 94-330) were cloned into BamHIEcoRI-digested pGEX-2TK (Pharmacia), a vector designed for the expression of GST fusion proteins in E. coli (this vector also encodes the recognition sequence for the catalytic subunit of bovine cAMP-dependent protein kinase, thus permitting radiolabeling of GST fusion proteins|. The expression vectors encoding histidine-tagged CBP (amino acids 1-682), CBP (amino acids 451-682), and p300 (amino acids 1-663), as well as those encoding GST-tagged CBP (amino acids 1680-1891) and p300 (amino acids 1642-1856), were gifts of J. Lundblad, R. Kwok, and R. Goodman (Lundblad et al. 1995).

\section{Mammalian expression plasmids and reporters}

Cytomegalovirus (CMV) promoter-driven expression vectors encoding human SREBP-2 (amino acids 1-462), Gal4 (amino 
acids 1-147), Gal4-rat CREB (amino acids 1-283), Gal4-human SREBP-2 (amino acids 1-330), and full-length mouse CBP were produced in pcDNA3.1 $(+)$ (Invitrogen). The inserts were prepared either by excision or PCR amplification from pXH-4 (Hua et al. 1993), pBS Gal4 (1-147) (Attardi and Tiian 1993), pRcRSVCREB341 (Loriaux et al. 1993), GST-SREBP-2 (amino acids 1-330) (described above), and pCMX-CBP (R. Kwok and R. Goodman, unpubl.l, respectively. Briefly, each construct was produced by a trimolecular ligation involving the above inserts (digested with NdeI-XbaI or NdeI-XhoI), a HindIII-NdeI-digested 110-bp DNA fragment derived from pT $\beta$-Stop (Jantzen et al. 1990) containing the $\beta$-globin translational leader sequence and a hemagglutinin epitope tag, and HindIII-XbaI- or HindIIIXhol-digested pcDNA3.1 $(+)$. The vector pCMV-Gal4-p53 (a gift of C. Thut, University of California, Berkeley, unpubl.) expresses a Gal4 DNA-binding domain fusion to two tandem copies of human p53 (amino acids 1-42). The vector pRc/CMV7Shamster SREBP-1 (amino acids 1-410) was generously provided by S. Scheek, M. Brown, and J. Goldstein (Sato et al. 1994). The protein kinase A expression construct pRSV-PKA (Maurer 1989) was kindly given to us by J. Lundblad (Oregon Health Sciences University, Portland).

The pLDL-Syn-TATA-luc reporter (Sanchez et al. 1995) contains an SREBP-responsive enhancer sequence derived from the LDL receptor promoter that has been placed upstream of a heterologous core promoter and the luciferase gene. This construct is derived from pSyn-TATA-luc, which lacks the LDL receptor enhancer sequences (Sanchez et al. 1995). Both vectors were kindly provided by T. Osborne. The pG2-TK-luc plasmid, which was produced by S. Hollenberg and V. Giguere from pBLCAT2 (Luckow and Schutz 1987), is a luciferase reporter containing two tandem Gal4 DNA-binding sites upstream of the herpes simplex virus thymidine kinase promoter.

\section{Purification and identification of p265}

Crude HeLa and Schneider cell nuclear extracts were produced according to the method of Dignam et al. (1983) and phosphocellulose (Whatman) fractionation was performed as described (Matsui et al. 1980). Anion exchange chromatography (Poros Q, Poros Corp.) was performed by fast protein liquid chromatography (FPLC; Pharmacia) with column loading at $0.1 \mathrm{M} \mathrm{KCl}$ HEMG (25 mM HEPES at $\mathrm{pH} 7.6,0.1 \mathrm{~mm}$ EDTA, $12.5 \mathrm{~mm}$ $\mathrm{MgCl}_{2}$, and $10 \%$ glycerol) and elution by salt gradient from 0.1 $\mathrm{M}$ to $1 \mathrm{M} \mathrm{KCl} \mathrm{HEMG.} \mathrm{All} \mathrm{HeLa} \mathrm{and} \mathrm{Schneider} \mathrm{cell} \mathrm{extracts} \mathrm{and}$ fractions were dialyzed to $0.1 \mathrm{M} \mathrm{KCl} \mathrm{HEMG} \mathrm{prior} \mathrm{to} \mathrm{incubation}$ with GST-SREBP affinity resins. GST fusion proteins were expressed in E. coli strain DH5 $\alpha$ and purified as described (Smith and Johnson 1988) using glutathione-agarose beads (Pharmacia). Diagnostic and preparative (see below) scale purifications of p265 using GST affinity resins were performed in essentially the same manner, except that beads used for the former purpose were eluted with Laemmli sample buffer (Laemmli 1970).

Preparative purification of p265 was performed as follows: A crude HeLa cell nuclear extract derived from 290 liters of suspension culture was fractionated by phosphocellulose chromatography, and the protein eluting at $0.3 \mathrm{M} \mathrm{KCl} \mathrm{HEMG} \mathrm{was} \mathrm{dia-}$ lyzed to $0.1 \mathrm{M} \mathrm{KCl} \mathrm{HEMG,} \mathrm{followed} \mathrm{by} \mathrm{the} \mathrm{addition} \mathrm{of} \mathrm{NP-40} \mathrm{to}$ a final concentration of $0.1 \%$. After ultracentrifugation and filtration $(0.22-\mu \mathrm{m}$ pore size), this protein was mixed with $7 \mathrm{ml}$ of GST-SREBP-2 (amino acids 1-330) affinity resin and nutated 3 $\mathrm{hr}$ at $4^{\circ} \mathrm{C}$. The beads were washed four times with $0.1 \mathrm{M} \mathrm{KCl}$ HEMG containing $0.1 \% \mathrm{NP}-40$, and bound proteins were eluted in batch for $1 \mathrm{hr}$ with $10 \mathrm{ml}$ of $2 \mathrm{M} \mathrm{NaCl}$ HEMG containing $0.01 \%$ NP- 40 . The eluate was concentrated by dialysis against PD buffer $(1 \mathrm{mM}$ Tris at $\mathrm{pH} 7.8,20 \%$ PEG $20,000,0.02 \%$ SDS, $0.01 \% \mathrm{NP}-40$, and $1 \mathrm{~mm} \mathrm{DTT}$, transferred to Eppendorf tubes, and further concentrated in an evaporation chamber (SpeedVac, Savant) until a final volume of $300 \mu \mathrm{l}$ was attained. The sample was separated by SDS-PAGE, transferred to a nitrocellulose membrane, and stained with Ponceau $S$ to permit excision of bands from the membrane. The band corresponding to $\mathrm{p} 265$ was digested with Lys-C endoproteinase (Wako), and the resulting peptides were purified by reversed phase chromatography and sequenced. The peptide sequences (shown in Fig. 2C) were used as templates to search protein sequence data bases using the National Center for Biotechnology Instruction (NCBI) BLAST search program.

\section{Western blotting}

Western blots were performed as described (Oliner et al. 1992) using rabbit polyclonal antiserum raised against CBP amino acid 455-600 (a gift of M. Montminy, Salk Institute, La Jolla, $\mathrm{CA}$, antiserum \#5614) at a 1:5000 dilution.

\section{Far Western blotting}

Proteins were separated by SDS-PAGE, transferred to nitrocellulose membranes, and incubated $1 \mathrm{hr}$ at room temperature in blocking buffer ( $25 \mathrm{~mm}$ HEPES at $\mathrm{pH} 7.6,25 \mathrm{~mm} \mathrm{NaCl}, 5 \mathrm{~mm}$ $\mathrm{MgCl}_{2}, 5 \%$ nonfat dry milk, $1 \mathrm{~mm} \mathrm{DTT}$, and $0.05 \% \mathrm{NP}-40 \mid$. The membranes were transferred to heat-seal bags and rocked overnight at $4^{\circ} \mathrm{C}$ in probe buffer $(20 \mathrm{~mm}$ HEPES at $\mathrm{pH} 7.6,75 \mathrm{~mm}$ $\mathrm{KCl}, 2.5 \mathrm{mM} \mathrm{MgCl}_{2}, 0.1 \mathrm{~mm}$ EDTA, $0.05 \% \mathrm{NP}-40$, and $1 \%$ nonfat dry milk; $5 \mathrm{ml}$ of probe solution per blot) containing $\sim \mathrm{l} \mu \mathrm{g}$ of radiolabeled GST fusion protein $3 \times 10^{6} \mathrm{cpm} / \mathrm{ml}$ of probe solution), as well as crude lysates from bacteria overexpressing GST-SREBP-1 (amino acids 91-323) or GST-SREBP-2 (amino acids 94-330) (to block nonspecific probe interactions). Membranes were washed (by rocking for $30 \mathrm{~min}$ at $4^{\circ} \mathrm{C}$ with $100 \mathrm{ml}$ of probe buffer lacking GST fusion proteins) and exposed to film or PhosphorImaging screen (Fuii).

GST fusion proteins were radiolabeled $\left(30 \mathrm{~min}\right.$ at $\left.30^{\circ} \mathrm{C}\right)$ in 30- $\mu$ l reactions containing $20 \mathrm{~mm}$ Tris $(\mathrm{pH} 7.5), 100 \mathrm{~mm} \mathrm{NaCl}$, $12 \mathrm{mM} \mathrm{MgCl}_{2}, 1 \mathrm{~mm} \mathrm{DTT}, 0.4 \mu \mathrm{l}$ of glutathione-agarose-bound GST fusion protein ( $\sim 2 \mu \mathrm{g}$ of protein), $10 \mu \mathrm{l}$ of Sepharose CL4B beads (Pharmacia; inert bead filler), $450 \mu \mathrm{Ci}\left[\gamma^{-{ }^{32}}\right.$ P]ATP (Amersham PB 15068), and six units of bovine heart muscle kinase (Sigma P-2645). After washing the beads four times with $1 \mathrm{ml}$ of GE buffer (100 $\mathrm{mm}$ Tris at $\mathrm{pH} 8.0,120 \mathrm{~mm} \mathrm{NaCl}, 0.1 \% \mathrm{NP}-40$ ), the radiolabeled proteins were eluted in GE buffer containing 20 $\mathrm{m} M$ reduced glutathione (Sigma G-4251).

\section{Transfections}

HeLa cell monolayers were seeded at $1 \times 10^{5}$ cells per well in six-well tissue culture plates (Falcon) 16-24 hr before $\mathrm{CaPO}_{4}$ mediated transfection (Sambrook et al. 1989). The media (Dulbecco's modified eagle media supplemented with $10 \%$ fetal bovine serum, $100 \mathrm{U} / \mathrm{ml}$ of penicillin, $100 \mathrm{U} / \mathrm{ml}$ of streptomycin, and $2 \mathrm{~mm}$ glutaminel were replaced $12-18 \mathrm{hr}$ after transfection; 30-36 hr later, the cells were harvested, lysed, and assayed for luciferase and $\beta$-galactosidase activity, as described previously (Wang and Tjian 1994).

\section{Acknowledgments}

We thank S. Scheek, M. Brown, and J. Goldstein for plasmids pXH-4 and pRc/CMV7S-hamster SREBP-1 (amino acids 1-410), as well as for helpful discussions; $\mathrm{T}$. Osborne for plasmids pSyn-TATA-luc, pLDL-Syn-TATA-luc, and pPac-hSREBP-1 (amino acids 1-490); J. Lundblad, R. Kwok, and R. Goodman for 
plasmids His-CBP (amino acids 1-682), His-CBP (amino acids 451-682), His-p300 (amino acids 1-663), GST-CBP (amino acids 1680-1891), GST-p300 (amino acids 1642-1856), pRcRSVCREB341, pRSV-PKA, and pCMX-CBP; M. Montminy for antiCBP serum; G. Cutler for expert advice in preparing figures; $\mathrm{K}$. Yokomori, S. Takada, and S. Ryu for the fractionated HeLa nuclear extracts used in pilot experiments; and S. Ryu, C. Thut, and A. Naar for critically reading the manuscript. This work was supported in part by grants from the Damon Runyon-Walter Winchell Cancer Research Fund (to J.O.) and the National Institutes of Health (to R.T.).

The publication costs of this article were defrayed in part by payment of page charges. This article must therefore be hereby marked "advertisement" in accordance with 18 USC section 1734 solely to indicate this fact.

\section{References}

Abraham, S.E., S. Lobo, P. Yaciuk, H.G. Wang, and E. Moran. 1993. p300 and p300-associated proteins are components of TATA-binding protein (TBP) complexes. Oncogene 8: 16391647.

Arany, Z., D. Newsome, E. Oldread, D.M. Livingston, and R. Eckner. 1995. A family of transcriptional adaptor proteins targeted by the E1A oncoprotein. Nature 374: 81-84.

Arias, J., A.S. Alberts, P. Brindle, F.X. Claret, T. Smeal, M. Karin, J. Feramisco, and M. Montminy. 1994. Activation of cAMP and mitogen responsive genes relies on a common nuclear factor. Nature 370: 226-229.

Attardi, L.D. and R. Tjian. 1993. Drosophila tissue-specific transcription factor NTF-l contains a novel isoleucine-rich activation motif. Genes \& Dev. 7: 1341-1353.

Bannister, A.J. and T. Kouzarides. 1995. CBP-induced stimulation of c-Fos activity is abrogated by E1 A. EMBO J. 14: 47584762.

Briggs, M.R., C. Yokoyama, X. Wang, M.S. Brown, and J.L. Goldstein. 1993. Nuclear protein that binds sterol regulatory element of low density lipoprotein receptor promoter. I. Identification of the protein and delineation of its target nucleotide sequence. J. Biol. Chem. 268: 14490-14496.

Brown, M.S. and J. L. Goldstein. 1980. Multivalent feedback regulation of HMG CoA reductase, a control mechanism coordinating isoprenoid synthesis and cell growth. I. Lipid Res. 21: 505-517.

- 1986. A receptor-mediated pathway for cholesterol homeostasis. Science 232: 34-47.

Chen, J.L., L.D. Attardi, C.P. Verrijzer, K. Yokomori, and R. Tjian. 1994. Assembly of recombinant TFIID reveals differential coactivator requirements for distinct transcriptional activators. Cell 79: 93-105.

Chrivia, J.C., R.P. Kwok, N. Lamb, M. Hagiwara, M.R. Montminy, and R.H. Goodman. 1993. Phosphorylated CREB binds specifically to the nuclear protein CBP. Nature 365: 855-859.

Dai, P., H. Akimaru, Y. Tanaka, D.X. Hou, T. Yasukawa, C. Kanei-Ishii, T. Takahashi, and S. Ishii. 1996. CBP as a transcriptional coactivator of c-Myb. Genes \& Dev. 10: 528-540.

Dignam, J.D., R.M. Lebovitz, and R.G. Roeder. 1983. Accurate transcription initiation by RNA polymerase II in a soluble extract from isolated mammalian nuclei. Nucleic Acids Res. 11: 1475-1489.

Dynlacht, B.D., T. Hoey, and R. Tjian. 1991. Isolation of coactivators associated with the TATA-binding protein that mediate transcriptional activation. Cell 66: 563-576.

Gill, G., E. Pascal, Z.H. Tseng, and R. Tjian. 1994. A glutamine- rich hydrophobic patch in transcription factor Spl contacts the dTAFII 10 component of the Drosophila TFIID complex and mediates transcriptional activation. Proc. Natl. Acad. Sci. 91: 192-196.

Goldstein, J.L. and M.S. Brown. 1977. The low-density lipoprotein pathway and its relation to atherosclerosis. Annu. Rev. Biochem. 46: 897-930.

- 1984. Progress in understanding the LDL receptor and HMG-CoA reductase, two membrane proteins that regulate the plasma cholesterol. J. Lipid Res. 25: 1450-1461.

. 1990. Regulation of the mevalonate pathway. Nature 343: $425-430$.

Goldstein, J.L., M.S. Brown, R.G. Anderson, D.W. Russell, and W.J. Schneider. 1985. Receptor-mediated endocytosis: Concepts emerging from the LDL receptor system. Annu. Rev. Cell Biol. 1: 1-39.

Goodrich, J.A. and R. Tiian. 1994. TBP-TAF complexes: Selectivity factors for eukaryotic transcription. Curr. Opin. Cell Biol. 6: 403-409.

Goodrich, J.A., T. Hoey, C.J. Thut, A. Admon, and R. Tijian. 1993. Drosophila TAFII40 interacts with both a VP16 activation domain and the basal transcription factor TFIIB. Cell 75: 519-530.

Harlow, E., P. Whyte, B.R. Franza Jr., and C. Schley. 1986. Association of adenovirus early region lA proteins with cellular polypeptides. Mol. Cell Biol. 6: 1579-1589.

Hua, X., C. Yokoyama, J. Wu, M.R. Briggs, M.S. Brown, J.L. Goldstein, and X. Wang. 1993. SREBP-2, a second basic-helix-loop-helix-leucine zipper protein that stimulates transcription by binding to a sterol regulatory element. Proc. Nat1. Acad. Sci. 90: 11603-11607.

Janknecht, R. and T. Hunter. 1996. Transcriptional control: Versatile molecular glue. Curr. Biol. 6: 951-954.

Jantzen, H.M., A. Admon, S.P. Bell, and R. Tjian. 1990. Nucleolar transcription factor hUBF contains a DNA-binding motif with homology to HMG proteins. Nature 344: 830-836.

Kamei, Y., L. Xu, T. Heinzel, J. Torchia, R. Kurokawa, B. Gloss, S.C. Lin, R.A. Heyman, D.W. Rose, C.K. Glass, and M.G. Rosenfeld. 1996. A CBP integrator complex mediates transcriptional activation and AP-1 inhibition by nuclear receptors. Cell 85: 403-414.

Kee, B.I., J. Arias, and M.R. Montminy. 1996. Adaptor-mediated recruitment of RNA polymerase II to a signal-dependent activator. J. Biol. Chem. 271: 2373-2375.

Klemm, R.D., J.A. Goodrich, S. Zhou, and R. Tjian. 1995. Mo lecular cloning and expression of the 32-kDa subunit of human TFIID reveals interactions with VP16 and TFIIB that mediate transcriptional activation. Proc. Natl. Acad. Sci. 92: 5788-5792.

Kwok, R.P., J.R. Lundblad, J.C. Chrivia, J.P. Richards, H.P. Bachinger, R.G. Brennan, S.G. Roberts, M.R. Green, and R.H. Goodman. 1994. Nuclear protein CBP is a coactivator for the transcription factor CREB. Nature 370: 223-226.

Laemmli, U.K. 1970. Cleavage of structural proteins during the assembly of the head of bacteriophage T4. Nature 227: 680685.

Lee, J.S., K.M. Galvin, R.H. See, R. Eckner, D. Livingston, E. Moran, and Y. Shi. 1995. Relief of YY1 transcriptional repression by adenovirus ElA is mediated by ElA-associated protein p300. Genes \& Dev. 9: 1188-1198.

Loriaux, M.M., R.P. Rehfuss, R.G. Brennan, and R.H. Goodman. 1993. Engineered leucine zippers show that hemiphosphorylated CREB complexes are transcriptionally active. Proc. Nat1. Acad. Sci. 90: 9046-9050.

Lu, H. and A.J. Levine. 1995. Human TAFII3I protein is a tran scriptional coactivator of the p53 protein. Proc. Natl. Acad. 
Sci. 92: 5154-5158.

Luckow, B. and G. Schutz. 1987. CAT constructions with multiple unique restriction sites for the functional analysis of eukaryotic promoters and regulatory elements. Nucleic Acids Res. 15: 5490.

Lundblad, J.R., R.P. Kwok, M.E. Laurance, M.L. Harter, and R.H. Goodman. 1995. Adenoviral E1A-associated protein p300 as a functional homologue of the transcriptional co-activator CBP. Nature 374: 85-88.

Matsui, T., J. Segall, P.A. Weil, and R.G. Roeder. 1980. Multiple factors required for accurate initiation of transcription by purified RNA polymerase II. I. Biol. Chem. 255: 1199211996.

Maurer, R.A. 1989. Both isoforms of the cAMP-dependent protein kinase catalytic subunit can activate transcription of the prolactin gene. J. Biol. Chem. 264: 6870-6873.

Oelgeschlager, M., R. Janknecht, J. Krieg, S. Schreek, and B. Luscher. 1996. Interaction of the co-activator CBP with $\mathrm{Myb}$ proteins: Effects on Myb-specific transactivation and on the cooperativity with NF-M. EMBO J. 15: 2771-2780.

Oliner, J.D., K.W. Kinzler, P.S. Meltzer, D.L. George, and B. Vogelstein. 1992. Amplification of a gene encoding a p53associated protein in human sarcomas. Nature 358: 80-83.

Onate, S.A., S.Y. Tsai, M.J. Tsai, and B.W. O'Malley. 1995. Sequence and characterization of a coactivator for the steroid hormone receptor superfamily. Science 270: 1354-1357.

Sakai, J., E.A. Duncan, R.B. Rawson, X. Hua, M.S. Brown, and J.L. Goldstein. 1996. Sterol-regulated release of SREBP-2 from cell membranes requires two sequential cleavages, one within a transmembrane segment. Cell 85: 1037-1046.

Sambrook, J., E.F. Fritsch, and T. Maniatis. 1989. Molecular cloning: A laboratory manual. Cold Spring Harbor Laboratory Press, Cold Spring Harbor, NY.

Sanchez, H.B., L. Yieh, and T.F. Osborne. 1995. Cooperation by sterol regulatory element-binding protein and $\mathrm{Spl}$ in sterol regulation of low density lipoprotein receptor gene. J. Biol. Chem. 270: 1161-1169.

Sato, R., J. Yang, X. Wang, M.J. Evans, Y.K. Ho, J.L. Goldstein, and M.S. Brown. 1994. Assignment of the membrane attachment, DNA binding, and transcriptional activation domains of sterol regulatory element-binding protein-1 (SREBP-1). J. Biol. Chem. 269: 17267-17273.

Sauer, F., S.K. Hansen, and R. Tjian. 1995. Multiple TAFIIs directing synergistic activation of transcription. Science 270: 1783-1788.

Smith, D.B. and K.S. Johnson. 1988. Single-step purification of polypeptides expressed in Escherichia coli as fusions with glutathione S-transferase. Gene 67: 31-40.

Thut, C.J., J.L. Chen, R. Klemm, and R. Tjian. 1995. p53 transcriptional activation mediated by coactivators TAFII40 and TAFII60. Science 267: 100-104.

Turner, B.M. 1993. Decoding the nucleosome. Cell 75: 5-8.

Wang, E.H. and R. Tjian. 1994. Promoter-selective transcriptional defect in cell cycle mutant ts 13 rescued by hTAFII2 20 . Science 263: 811-814.

Wang, X., M.R. Briggs, X. Hua, C. Yokoyama, J.L. Goldstein, and M.S. Brown. 1993. Nuclear protein that binds sterol regulatory element of low density lipoprotein receptor promoter. II. Purification and characterization. I. Biol. Chem. 268: 14497-14504.

Wang, X., R. Sato, M.S. Brown, X. Hua, and J.L. Goldstein. 1994. SREBP-1, a membrane-bound transcription factor released by sterol-regulated proteolysis. Cell 77: 53-62.

Wolffe, A.P. 1994. Nucleosome positioning and modification: Chromatin structures that potentiate transcription. Trends Biochem. Sci. 19: 240-244.
Yang, X.-J., V.V. Ogryzko, J. Nishikawa, B.H. Howard, and Y. Nakatani. 1996. A p300/CBP-associated factor that competes with the adenoviral oncoprotein E1A. Nature 382: 319-324.

Yee, S.P. and P.E. Branton. 1985. Detection of cellular proteins associated with human adenovirus type 5 early region $1 \mathrm{~A}$ polypeptides. Virology 147: 142-153.

Yokoyama, C., X. Wang, M.R. Briggs, A. Admon, J. Wu, X. Hua, J.L. Goldstein, and M.S. Brown. 1993. SREBP-1, a basic-helixloop-helix-leucine zipper protein that controls transcription of the low density lipoprotein receptor gene. Cell 75: 187197.

Yuan, W., G. Condorelli, M. Caruso, A. Felsani, and A. Giordano. 1996. Human p300 protein is a coactivator for the transcription factor MyoD. J. Biol. Chem. 271: 9009-9013. 


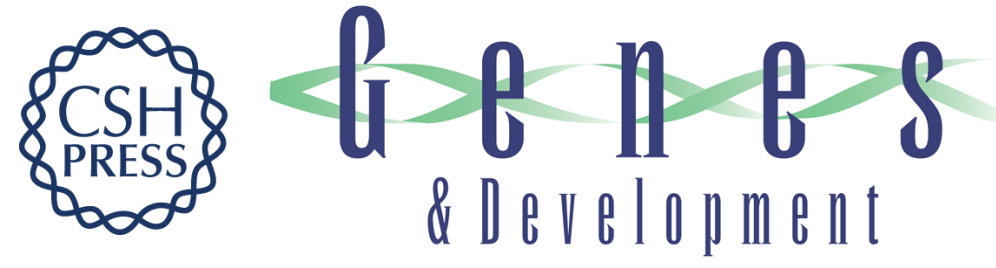

\section{SREBP transcriptional activity is mediated through an interaction with the CREB-binding protein.}

J D Oliner, J M Andresen, S K Hansen, et al.

Genes Dev. 1996, 10:

Access the most recent version at doi:10.1101/gad.10.22.2903

References This article cites 54 articles, 23 of which can be accessed free at:

http://genesdev.cshlp.org/content/10/22/2903.full.html\#ref-list-1

License

Email Alerting

Service

Receive free email alerts when new articles cite this article - sign up in the box at the top right corner of the article or click here.

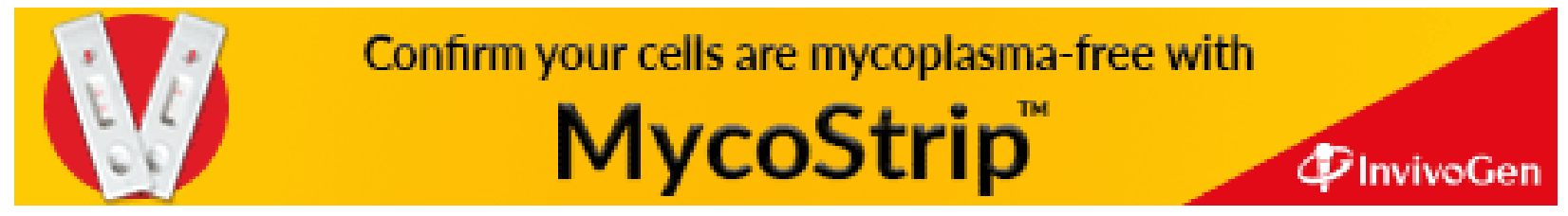

